\title{
Q -2348 Effects of nitrate exposure on the functional structure of a microbial community in a uranium-contaminated aquifer
}

Ridge, TN, ${ }^{5}$ Georgia Institute of Technology, Atlanta, GA, ${ }^{6}$ Lawrence Berkeley National Laboratory, Berkeley, CA.

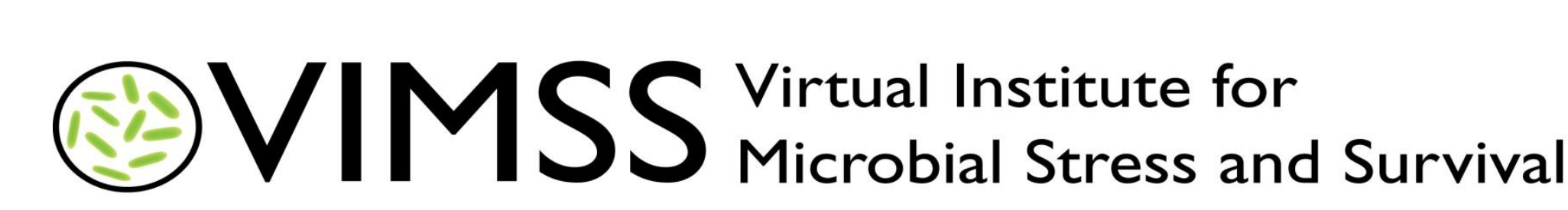

OAKRIDGENATIONAL LABORATORY

Results

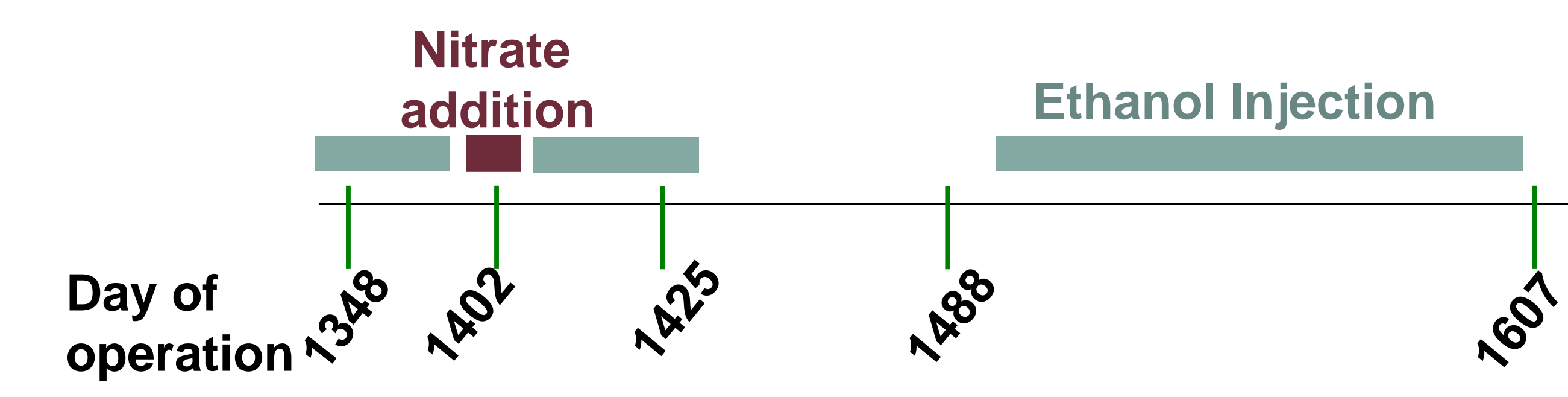

Geochemical Analysis of Groundwater Samples in FW101-2 and [FW102-2] ( $\mu$ M) Day \# $\mathrm{COD}^{\mathrm{a}}$ Sulfate Sulfide Iron $\mathrm{pH}$ Nitrate $\mathrm{U}(\mathrm{VI})$ Nitrite $\mathrm{NH}_{4}-\mathrm{H}$ $\begin{array}{lllllllllll}1348 & 101 & 547 & 689 & 14 & 6.2 & 1 & 0.065 & 0 & 20\end{array}$ $\begin{array}{cccccccccc}1402 & 0 & 1680 & 0 & 23 & 6.1 & 2042 & 0.936 & 56 & 51 \\ 1425 & 67 & 1229 & 0 & 21 & 6.6 & 362 & 3.602 & 66 & 46\end{array}$ $\begin{array}{cccccccccc}1488 & 0 & 1694 & 0 & 0 & 6.1 & 13 & 0.397 & 0 & 0 \\ & {[0]} & {[1687]} & {[0]} & {[0]} & {[6.4]} & {[22]} & {[0.485]} & {[0]} & {[0]}\end{array}$ $\begin{array}{cccccccccc}1607 & 3 & 1136 & 41 & 14 & 6.2 & 13 & 0.259 & 0 & 10 \\ & {[4]} & {[1007]} & {[38]} & {[30]} & {[6.2]} & {[5]} & {[0.140]} & {[0]} & {[0]}\end{array}$ ${ }^{a} \mathrm{COD}$, chemical oxygen demand $-\mathrm{a}$ measure of ethanol concentration

\begin{tabular}{|c|c|c|c|c|c|c|c|}
\hline Sample & & & & & & & \\
\hline name & 1348 & 1402 & 1425 & 1488 & 1607 & $\begin{array}{l}102-2 \\
1488\end{array}$ & $\begin{array}{l}102-2 \\
1607\end{array}$ \\
\hline 1348 & $\mathrm{X}$ & $17.67 \%$ & $28.03 \%$ & $14.47 \%$ & $19.77 \%$ & $3.22 \%$ & $5.69 \%$ \\
\hline 1402 & & & $15.06 \%$ & $6.12 \%$ & $57.61 \%$ & $7.49 \%$ & $28.39 \%$ \\
\hline 1425 & & & & $16.49 \%$ & $17.54 \%$ & $3.04 \%$ & $4.61 \%$ \\
\hline 1488 & & & & & $7.84 \%$ & $2.39 \%$ & $3.27 \%$ \\
\hline 1607 & & & & & & $4.71 \%$ & $12.14 \%$ \\
\hline $\begin{array}{l}102-2 \\
1488\end{array}$ & & & & & & & $44.18 \%$ \\
\hline $\begin{array}{l}1402-2 \\
102-2\end{array}$ & & & & & & & 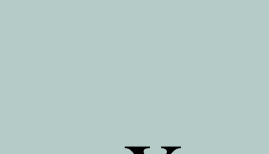 \\
\hline 1607 & & & & & & & X \\
\hline Richness & 250 & 1135 & 225 & 114 & 780 & 487 & 864 \\
\hline Shannon & 510 & 660 & 506 & 417 & 622 & 572 & 626 \\
\hline
\end{tabular}
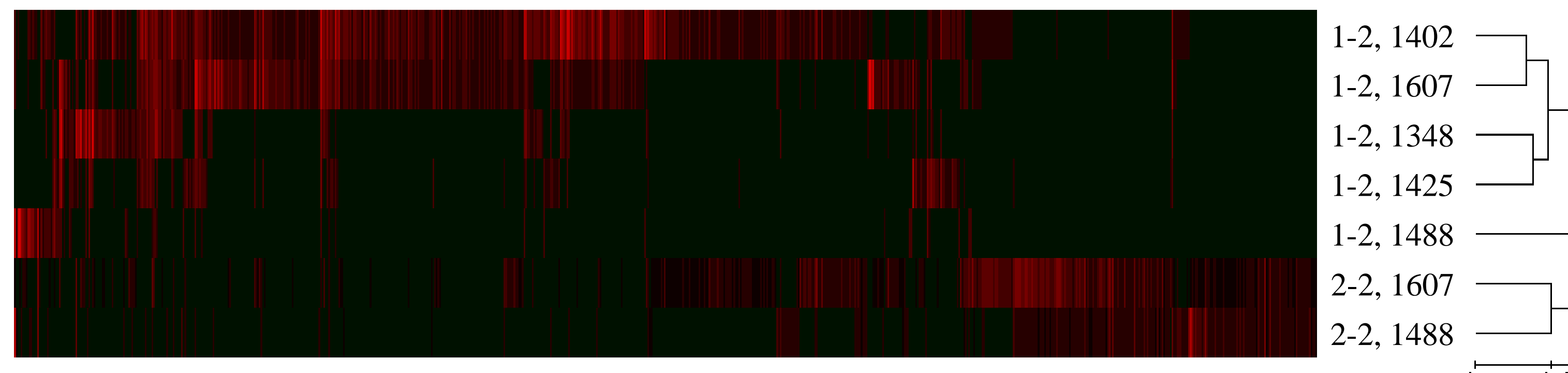

Hierarchical cluster analysis of all genes detected by GeoChip for FW101-2 and

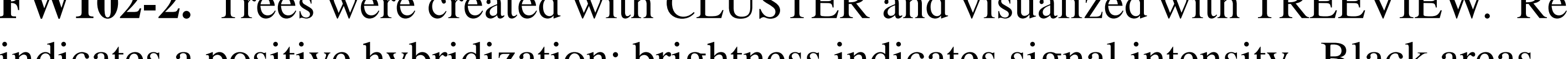
represent no hybridization above background level. 1-2, FW101-2:2-2, FW102-2: numbers indicated operational day.

FW101-2 and FW102-2 show very different community profiles, indicating different community composition in each well.

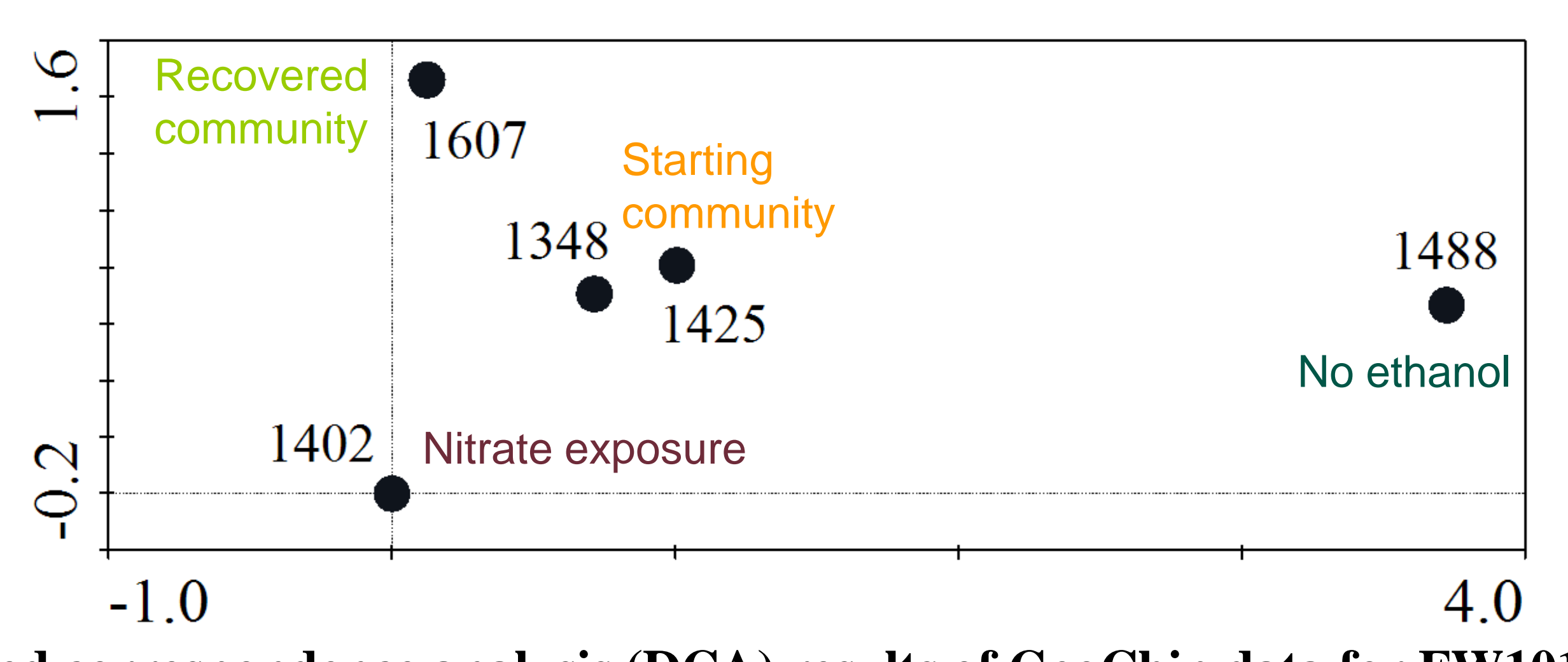

Detrended correspondence analysis (DCA) results of GeoChip data for FW101-2. A transient shift in community structure was observed after introduction of nitrate. Lack
ethanol had a much greater impact on the community structure, but after ethanol was restarted, the community recovered and was more similar to the original community.

\section{Berkeley (}

http://vimss.lbl.gov/

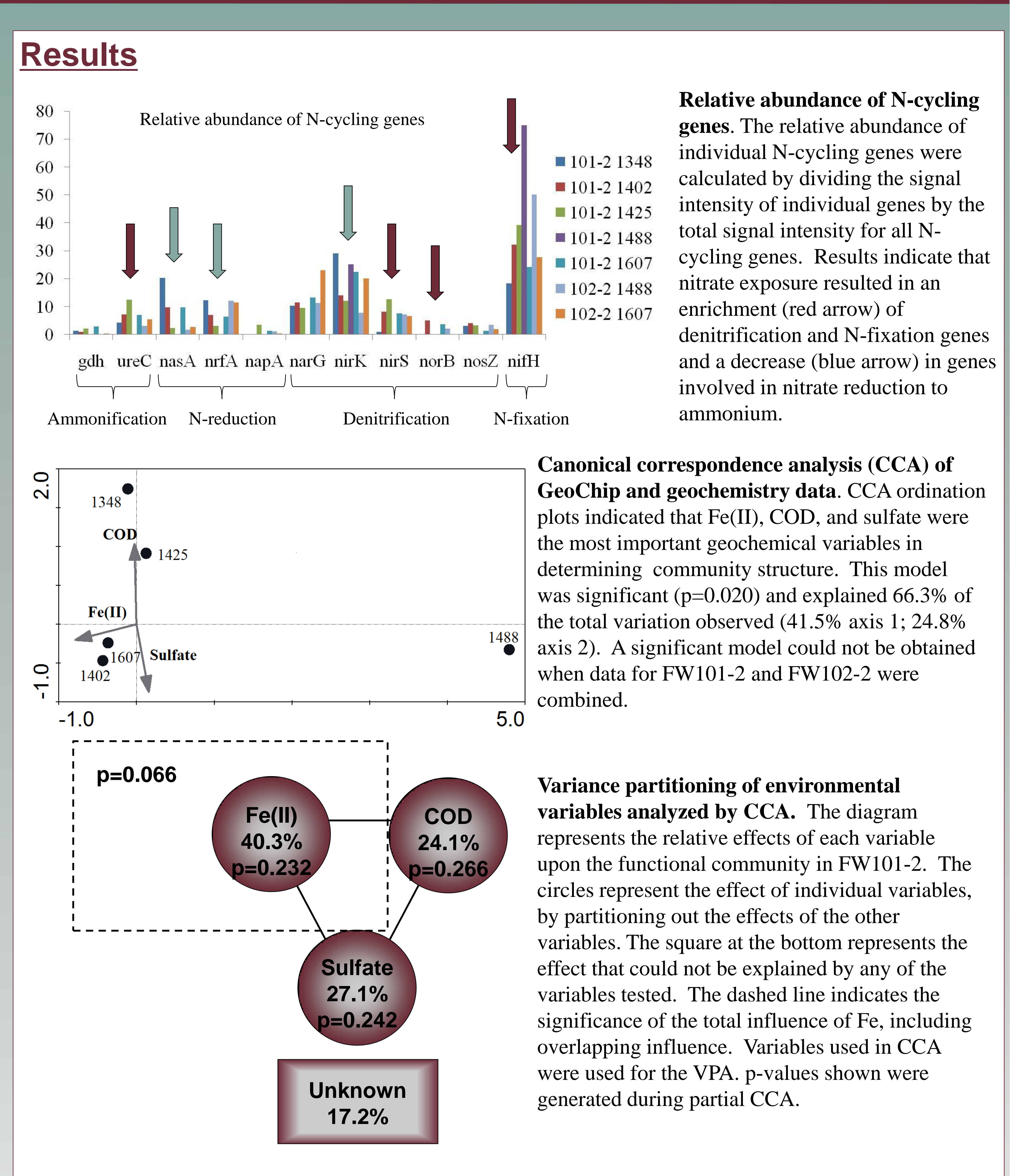

Summary

Introduction of nitrate caused an increase in $\mathrm{U}(\mathrm{VI})$ concentrations indicating the reoxidation of the reduced

Clustering results indicated that communities in the two sampling wells were quite different.

A transient shift in community structure was observed after nitrate exposure. However, a larger shift was observed in the absence of ethanol addition compared to that observed in the presence of nitrate. During nitrate exposure and immediately following cessation of nitrate, an increase in abundance of genes
involved in denitrification and nitrogen fixation was noted concurrently with a decrease in genes involved in involved in denitrification and
nitrate reduction to ammonium

$\mathrm{COD}$, Fe(II), and sulfate had the most influence on the community structure with Fe having the greatest influence.

Overall, nitrate did have an effect on the microbial community at this site but lack of ethanol had a much greater original community.

\section{Contact Information}

Joy Van Nostrand - joy.vannos

Acknowledgements

ENIGMA is a Scientific Focus Area Program supported by the U. S. Department of Energy, Office of Science,
Office of Biological and Environmental Research, Genomics:GTL Foundational Science through contract DE AC02-05CH11231 between Lawrence Berkeley National Laboratory and the U.S. Department of Energy. 